http://dx.doi.org/10.4314/gjl.v4i2.5

\title{
THE MANAGEMENT OF WRITER-READER INTERACTION IN NEWSPAPER EDITORIALS
}

\author{
Mamonaheng Francina Selloane Ntsane
}

\begin{abstract}
This study investigates the management of interaction between the writer and the readers in newspaper editorials. It aims at exploring how editorial writers include the readers as participants in the discourse while maintaining their authorial persona. It investigates how the readers are aligned and disaligned with the views of the writer. Using the Engagement system of the Appraisal framework (Martin 2000, and Martin and White 2005), the study explores how dialogically expansive and contractive resources are used in this respect in editorials from different newspapers.

The study employed both qualitative and quantitative approaches. The findings show that contractive resources are slightly more used than expansive resources. The slight difference suggests that the editorial writers try to maintain a balance between bringing in the readers in a communicative event and maintaining their authority as the writers. The findings also indicate that Engagement resources are used in the same way by different newspapers. There is also no clear difference between newspapers from Lesotho and South Africa. This is because Public Eye (Lesotho), Sunday Times and Mail Guardian (both from South Africa) use the same style. Lesotho Times (Lesotho) is the only paper using a different style. It follows a more conversational tone and its arguments are somewhat subjective.
\end{abstract}

Keywords: appraisal, engagement system, dialogic contraction, dialogic expansion

\section{Introduction}

The term 'interaction' refers to a dialogic pattern where the sender and the receiver are regarded as participants in a discourse. Since written discourse is different from face-to-face interaction, a writer shows interaction with the readers through the use of linguistic resources. The writer shows awareness of his/her readers by pulling them into the discourse as participants. Bakhtin (1986: 91) views written discourse as engaging with the audience by responding to something, affirming something, anticipating possible responses or objections, and seeking support. He asserts that the dialogic nature of a text recognises the existence of other worlds outside that of the 
speaker or writer. That is, certain uses of language maximise dialogic space by initiating responses from the addressee, while other uses attempt to limit or restrict dialogue in that they do not prompt any response, such as in the case where the speaker anticipates an encountering response. In such situation, "the entire utterance is constructed, as it were, in anticipation of encountering this response" (Bakhtin 1986: 94). In some cases, the speaker/writer tries to channel the response in the way that the speaker/writer wishes.

In the same manner, Thompson (2001: 60) views a text as a record of a dialogue between the writer and the reader in that the writer enacts the roles of both participants in the unfolding dialogue. That is, writers attempt to guess what kind of information the readers expect from a text and they also anticipate the readers' questions or reactions to what is written. Thus, the writer can create solidarity by demonstrating an understanding of the reader's attitude towards a certain issue. Alternatively, the writer can manipulate the reader by spelling out questions that the 'corporate' reader ought to be expecting to be answered and therefore, encouraging the reader to accept the direction that the text is taking.

When writing a text, Thompson (2005: 312 ) points out that the writer needs to successfully construct a coherent text and an appropriate persona in a given text. Furthermore, the writer should convey an authoritative tone to persuade the readers of his/her expertise and knowledge of the subject, while at the same time showing an appropriate awareness of the readers. That is, in a communicative event, there is a need to maintain a balance between showing authority within a communicative event while at the same time acknowledging the possibility of an alternative voice.

\section{Theoretical Framework}

The study is based on the theory of Appraisal developed by Martin (2000) and later revised by Martin and White (2005). According to Martin and White (2005), Appraisal is concerned with how writers or speakers approve or disapprove, support, abhor, applaud and criticise and with how they position their readers to do likewise. It is concerned with construction of shared feelings and values and how linguistic resources are used to create shared emotions and values. Appraisal is concerned with how writers take particular authorial roles or identities, as well as with how they align or disalign themselves with potential readers. In the context of this study, Appraisal refers to the willingness of the writer to entertain divergent or convergent positions or to open a platform for a dialogue.

The Appraisal Theory proposes a taxonomy which includes the system of Attitude, Graduation and Engagement. The focus of the study is the Engagement system. According to Martin and White (2005: 107), Engagement comprises all locutions which provide the means for the authorial voice to position itself with 
respect to other voices and hence to engage with alternative voices in a communicative context. That is, these are the resources through which the speaker adopts a particular position and how they interact with potential readers. Engagement resources are interactive in that they acknowledge the presence of other voices by engaging with alternative views. The role of Engagement resources is to regulate the dialogic space in the sense that they are a means by which textual voice represents itself by acknowledging, engaging with, challenging or aligning itself with other utterances.

Within the system of Engagement, there are two main broad categories: Heteroglossia and Monoglossia. Heteroglossia gives an allowance for alternative viewpoints, whereas Monoglossia does not allow for viewpoints other than the author's. Monoglossic utterances are basically known as "bare assertions". However, Monoglossic texts are considered to be dialogic in that they make certain presuppositions about the audience's point of view (White 2001:18, Martin and White 2005:102). The focus of this chapter is exclusively Heteroglossia.

Heteroglossic utterances are further divided into dialogic expansion and dialogic contraction. Within this framework, dialogic expansion refers to the degree in which an utterance opens a dialogic space for alternative voices. It refers to the way in which the author opens a space for dialogue. There are two main categories of dialogic expansion: entertain and attribute (Martin and White 2005: 102).

According to Martin and White, dialogic contraction refers to the way in which an utterance actively challenges, refutes or restricts dialogic space. Dialogic contraction is divided into two main sub-categories: Disclaim and Proclaim. Disclaiming resources are a way through which a text positions itself as being at odds with or rejecting a contrary position. This is done through negation (Disclaim: Deny) and concession (Disclaim: Counter). The resources of Proclaim, on the other hand, allow the speaker to subscribe to a particular position, in some cases ruling out competing or alternative ones. That is, these resources limit the scope of dialogic alternatives in the on-going discourse. Proclaim comprises three sub-types namely, Concur, Pronounce and Endorse (2005:117).

The current study aims at identifying Engagement resources that are used in newspaper editorials and also how these resources are used. It also tries to identify the relationship between the choice of editorial genre and the choice of the used resources.

\section{Methodology}

The study on which this chapter is based employed both qualitative and quantitative approaches. The qualitative method involves an in-depth, detailed analysis of texts. In particular, this approach allows insights into the texts that are not 
available through a quantitative approach. The close analysis of texts has been useful in this study in exploring the way Engagement resources were used in the editorials to manage interaction between the writer and the reader. In the quantitative method, the approach is on the frequencies or numbers in order to arrive at an overall picture of the distribution of the resources. The approach has been useful in identifying Engagement resources used in editorials and, more importantly, in the comparative analysis.

The data for this chapter were collected mainly from printed newspapers. It was collected from a sample of 44 newspaper editorials from Lesotho (Public Eye and Lesotho Times) and South Africa (Sunday Times and Mail and Guardian). The researcher also used online editorials when it was difficult to get hold of some newspaper publications. The sample included editorials that were published every first week of the month. This sampling technique allowed elimination of bias. It avoided a selection of interesting topics or the area of interest only. It also provided a wider scope of issues covered in each newspaper within that period. It was observed that the topics of the editorials are mainly political. The study first identified the engagement resources used in these newspaper editorials and then compared their use in individual newspapers in order to establish the similarities and differences in employment of the Engagement resources in Lesotho and South African newspapers.

\section{Analysis of Expanding Resources}

Table 2 shows that of dialogically expansive resources, Entertain was the most frequently used. It occurs three times as frequently as other expansive resources. In this category: "...the authorial voice indicates that its position is but one of a number of possible positions and thereby, to a greater or lesser degree, makes dialogic space for these possibilities" (Martin and White 2005: 104).

Table 2: The overall use of Expanding Resources

\begin{tabular}{|l|l|l|l|}
\hline \multicolumn{4}{|c|}{ Expanding Resources } \\
\hline \multirow{2}{*}{ Newspaper } & Entertain & Attribution \\
\cline { 3 - 4 } Lesotho Times & $128(45 \%)$ & Acknowledge & Distance \\
\hline Mail \& Guardian & $50(18 \%)$ & $23(26 \%)$ & 0 \\
\hline Public Eye & $57(20 \%)$ & $23(20 \%)$ & 0 \\
\hline Sunday Times & $48(17 \%)$ & $25(28 \%)$ & $2(100 \%)$ \\
\hline Total & $280(100 \%)$ & $89(100 \%)$ & 0 \\
\hline
\end{tabular}

Within dialogically expansive resources, Modality is one of many strategies 
that the editorial writers use to open up the dialogic space. It opens up a dialogic space by entertaining other possibilities. Editorial writers use modals of probability to show the possibility of something happening or possibility of something happening presently, in the past or in future, thus opening up dialogic space, as there is no guarantee that something will happen. Examples (1) and (2) illustrate this point.

(1) The power battles that ravaged the party are likely to persist (LT).

(2) The student's defiance, and determination to see the school principal sacked was not only shocking for pupils still so young, but also reflected badly on their parents who should have intervened timeously and ensured that classes continued while whatever problems that might have existed, were being looked into (PE)

There is also the use of modal expressions that show capability or ability, as shown in examples (3) and (4). These modals are used to open up dialogic space for divergent or convergent views.

(3) Her failure to do so can only strengthen the hooligans' hand, as it paints them as being so powerful that even a national minister is afraid of venturing into the area (ST).

(4) The new LCD leadership has a chance to show that it can heal the wounds of the vicious fights, unite the party and win this election on the bases of policies (LT).

Other modal expressions that were frequently used are those that are referred to as strong modals. They include modals of recommendation, necessity and obligation, as in examples (5) to (7).

(5) Election observers and monitors from the regional bloc must be on the ground weeks before the actual voting (LT).

(6) But we urgently need a sense that South Africa is more than a sum of its divisions -racial, financial or factional... (M\&G).

(7) It should realise that, until it answers the public's legitimate questions, this story will not just go away (ST).

Although less obviously dialogically expansive, these modal expressions are classified as values for Entertain as they are individually based. As a result, they are subjective. According to Martin and White (2005: 111), these modals explicitly ground the demand in the subjectivity of the speaker; the obligation is based on the assessment by the speaker.

The use of high values of modals of obligation and recommendation, as seen in examples (6) to (7), is far more pronounced in Lesotho Times while in other papers, 
these high values of modals of obligation are used in moderation. This preference, according to White (2001: 3), is linked with more powerful speakers in an unequal status relationship. This means that, instead of treating the readers or the addressee on equal footing, as mentioned earlier, Lesotho Times takes an opportunity to influence or coerce or sway the readers in the direction that it wishes. These modals often portray a relationship of control and compliance/ resistance rather than a relationship of offering information or viewpoints. Thus, in this case the writer/speaker seeks to control the actions of the reader/ addressee.

In the Entertain category, there is also a frequent use of mental process verbs. These verbs are dialogic because they show a subjective view of the speaker through a strong commitment to the proposition. However, the speaker still recognises that there are people who may not share the same view, as in examples (8) to (9).

(8) We believe time has come to deliver a better, much more meaningful life to our people (LT).

(9) We doubt that any additional value will come from investigations now under way into what the government must- and should- have known many months ago (M\&G).

The use of these mental verbs in some cases is meant to show anticipation or an objection of divergent views; in that case the views are used to fend off the objection. When used in that way, the mental verbs are categorised as dialogically contractive in that they limit dialogic space for alternative views. This is discussed further in later sections.

Apart from the use of mental process verbs there is also the use of evidentials. Evidentials are used to show that the proposition put forward is but one of many. Therefore, dialogic space is expanded for such alternatives, as seen in examples (10) to $(11)$.

(10) This calculated political assault on the Constitutional court...appears to have been brought about by a succession of rulings against the state (ST).

(11) The paranoid, it seems, have taken control of the asylum, imposing on the entire country a regime of insane inverted rules $(M \& G)$.

Although low in frequency, highly committed forms such as "certainly", as in example (12), are used.

(12) Their demands are certainly justified (LT).

The use of the intensifier certainly is dialogically expansive, as it shows an element of doubt on the part of the speaker. Halliday (1994: 362), for example, remarked "we 
only say we are certain when we are not". Such forms are said to disguise an element of doubt in relation to the point of view being advanced.

Moving from the Entertain category, Acknowledge under Attribution was the second most frequently used in the dialogically expansive category. Acknowledgements are obviously dialogic in that they bring other voices into the text and represent the authorial voice as engaging with other voices. Martin and White (2005: 115) make a distinction between neutral and non-neutral attribution. In neutral attribution, the writer does not show alignment with the material being attributed and this type is typical of hard news. On the other hand, non-neutral attributions are more implicated in the issues of solidarity and alignment, as the writers explicitly show their stance towards the attributed material; this is typical of argumentative texts such as editorials. These types of attributions were most frequent in Lesotho Times editorials than in other newspaper editorials. Non-neutral attributions are illustrated in examples (13) to (15).

(13) The proponents of such dire purges argue that this will create stability and unity in the ANC (M\&G).

(14) ...the ANC's senior administrator, Gwede Mantashe, made the astonishing statement that "what the ANC cannot win in the courts it will win in the street (ST).

(15) Last week, the association made a halfhearted announcement Vodacom had allegedly committed themselves to bankrolling all the country's four leagues, once again (PE).

There are also neutral attributions where the authorial voice has used communicative process verbs such as said, argued, reported, stated, insisted and suggested, as is the case in examples (16) and (17) .

(16) Weinberg argued that he was merely presenting the written submission which had already been approved by the committee for the session (ST).

(17) Public Works announced that it is investigating who leaked embarrassing internal documents on the Nkandla development $(M \& G)$.

Unlike examples (12) and (15), examples (16) and (17) illustrate neutral attributions in that the reporting verbs record what actually happened. The authorial voice is disassociated from the proposition of the attributions; therefore the reader may interpret the writer as having "nothing investing the position being advanced in the reported material" (White 2005: 115). These types of attributions allow the writer to become detached from relationships of alignment and disalignment. 
There are also formulations which are categorised as hearsay. In this case as well, the authorial voice does not seek to influence the reader, as the reader might regard the attributed material as unfounded. The attributed material may, however, be believable to the readers as they are believed by the authorial voice, since it carries some authority. In this case, the dialogic space is opened for alternative voices: the writer brings into the texts other voices and engages with them interactively, as illustrated in example (18).

(18) This, we are told, is exactly what has happened at ST James- a place where fear has now made teachers and learners so suspicious of each other (PE).

The category of Attribute: distance involves formulations in which the writer explicitly distances the authorial voice from the attributed material (Martin and White 2005: 113). This is the least frequently used sub-category of Attribution, as illustrated in examples (19) and (20).

(19) Those who claim to be privy to the goings-on went even further by posting the flag of this new party (LT).

(20) It claims [that] it cannot speak freely because some requested information is market sensitive, even while it plays host to an unfolding, slow-motion train wreck $(M \& G)$.

In example (19), the writer detaches him/herself from the group that "claims" to know what is going on in the LCD party. As a result, the authorial voice distances him/herself from the claims made by this group. This came after there were rumours that the party was going to split. Nobody knew whether this was true or not but there were people on the inside who could tell what was going on. Instead of putting it as a fact, the writer only considered the "goings-on" as claims. That is, the writer distances himself from the claims of the party split. In example (20), however, the writer disassociates him/herself from the actual attribution.

The Analysis of Dialogically Contractive Resources

Table 3: The overall use of Contracting Resources

\begin{tabular}{|l|c|c|l|l|c|}
\hline & \multicolumn{2}{|c|}{ Disclaim } & \multicolumn{3}{c|}{ Proclaim } \\
\hline Newspaper & Deny & Counter & \multicolumn{1}{c|}{ Concur } & Pronounce & Endorse \\
\hline $\begin{array}{l}\text { Lesotho } \\
\text { Times }\end{array}$ & $75(40.0 \%)$ & $33(31.1 \%)$ & $\begin{array}{l}10 \\
(40.0 \%)\end{array}$ & $38(57 \%)$ & $2(25.5 \%)$ \\
\hline $\begin{array}{l}\text { Mail \& } \\
\text { Guardian }\end{array}$ & $36(19.0 \%)$ & $27(25.4 \%)$ & $6(24.0 \%)$ & $13(19.4 \%)$ & $3(37.5 \%)$ \\
\hline
\end{tabular}




\begin{tabular}{|l|l|l|l|l|l|}
\hline Public Eye & $41(22.0 \%)$ & $20(19.0 \%)$ & $9(36.0 \%)$ & $11(16.4 \%)$ & $3(37.5 \%)$ \\
\hline $\begin{array}{l}\text { Sunday } \\
\text { Times }\end{array}$ & $35(19.0 \%)$ & $25(24.0 \%)$ & 0 & $5(7.4 \%)$ & 0 \\
\hline Total & $187(100 \%)$ & $105(100 \%)$ & $25(100 \%)$ & $67(100 \%)$ & $8(100 \%)$ \\
\hline
\end{tabular}

Table 3 indicates that overall, disclaiming resources are employed more than proclaiming resources. This is probably because most of the editorial comments were criticising the government, political leaders, service delivery institutions and other social actors. In the Disclaim category, the more frequently used sub-category is that of Disclaim: Deny (64 percent) than Disclaim: Counter (46 percent). Dialogic alternatives are confronted, overwhelmed or otherwise excluded. Denial is used to reject claims/beliefs/views of others, as seen in the examples (21) and (22).

(21) It should also have communicated more clearly its belief that the song is a historical artefact, not a contemporary rallying cry $(\mathrm{M} \& \mathrm{G})$.

(22) The government cannot arm-twist employers to pay unsustainable wages (LT).

Denial is also used to respond to actions of others with reference to something that should have been done but was not done and it is also used to show something that happened (at the time of publication) that should have not happened, as illustrated in examples (23) and (24).

(23) Perhaps because he did not declare strongly enough his support for Zuma, he is now an enemy: you're either for Zuma or against him (ST).

(24) Never in its history has the LCD become such a playground for power hungry political schemers (LT).

The findings have also revealed that Denial can be directed towards the third party, away from the current writer-reader relationship, as demonstrated in example (25).

(25) A meeting held yesterday by members of JSC failed to come-up with a position on what action to take with regards to the issue (PE).

In this case, the non-act is performed by the JSC, which is the third party in the communicative event. The reader, who is the second party in the event, is being informed by the writer. In such cases, the reader is assumed to be taking the same stance as the writer who informs the reader and, in turn, the reader accepts the information. 
In other cases, the denial is against the addressee/reader specifically against the views/beliefs which the writer assumes that at least some of the members of his/her audience will be subject to, as seen in example (26).

(26) It is no exaggeration to say they have forever changed the way the world views those who have lost one or both limbs (ST).

Here the writer anticipates possible objections from a putative reader. As a result, the writer minimises the space for such objections. The writer probably anticipates that the readers will think that he/she is exaggerating. Thus, he minimises dialogic space for that. By fending off the objections, the writer directly engages with the readers and the readers are seen as aligned with the writer.

The sub-category of Disclaim: Counter also features in newspaper editorials. Countering options is dialogic in the same way as denials in that they invoke a contrary position which is said not to hold and they project particular beliefs or expectations onto the reader, as illustrated in (27) and (28).

(27) In spite of that admission he inexplicably still went ahead and issued an order for her release (LT).

(28) With such damning allegations against him, they should have long demanded his suspension. However, they seem hell-bent on shielding him at all cost (ST)

Within this sub-category, there were also rhetorical pairs of Deny: Counter. All the newspapers make use of these pairs. The resources of Disclaim: Deny and Counter project on to the reader particular beliefs or expectations. According to White (2005: 120), countering resources are mostly aligning in that they construe the writer as sharing particular beliefs with the reader, as seen in example (29).

(29) We do not need a charismatic authoritarian to weld us together under a nationalist flag, or a singer of lullabies to urge us to find unity in diversity. But we urgently need a sense that South Africa is more than the sum of its divisions - racial, financial or factional - and that we know, for all of our manifold difficulties, where we are going $(M \& G)$.

In this case, the denial rejects certain assumptions of the needs of the community (as affirmed by the inclusive pronoun we) and then the counter which affirms the assumed relationship. The writer here aligns the authorial voice with the readers by representing himself as conveying 'community concerns' rather than his own, individual views. 
Sunday Times, on the other hand makes an unusual combination of Entertain+ Counter+ Deny (although not in that particular order), as seen in examples (30) and (31).

(30) There seems to be a concerted effort from some of the country's most powerful politicians, not only to save Mdluli from criminal prosecution, but to see him become the country's top cop (ST).

(31) With such damning allegations against him, they should have long demanded his suspension. However, they seem hell-bent on shielding him at all cost (ST).

The paper appears to be mitigating the force of its accusations. This could be because Mdluli (at that time) was yet to be found guilty, and therefore the paper did not want to accuse anybody of something that had not yet been proven. However, if indeed Mdluli was being protected, whether he was guilty or not, the paper could have pointed out the facts as they are. In the end, they would be protecting him because he was innocent or guilty. Here the paper failed to take a stance, and as such failed to position the reader by allowing space for divergent views when it should have not.

Also occurring are resources of Proclaim through which the writers represented the authorial voice as highly warrantable and thus limit a space for alternative views. Within this category the authorial voice in this particular case has shown personal investment in the views being advanced and increased interpersonal cost for alternative views. These are called subjective pronouncements, which show a subjective assessment on the part of the writer/speaker as seen in examples (32) and (33).

(32) We know that Mdluli has written to Zuma declaring his loyalty and complaining of plots against him by other senior police officials (MG).

(33) We believe time has come to deliver a better, much more meaningful life to our people (LT).

There are also objective pronouncements, which are said to be more authoritative. According to Love (2011: 412), these kinds of expressions "strengthen the writer's claims for their factual knowledge". These types of expressions are common in all four newspaper editorials, as can be seen in examples (34) to (35).

(34) Clearly, the justices of the court were in awkward position. They had a direct interest in the outcome of the case $(M \& G)$. 
(35) With an election just two months away it is important that the regional bloc acts as an effective mid-wife in helping deliver a credible election that does not produce a contested result (LT).

Although the writers present the propositions as facts and highly warrantable, they nonetheless acknowledge that there may be alternative positions while challenging or fending-off those alternatives. Pronouncements could show that the writer is engaging in a dialogue with previous speakers/writers and the writer refutes whatever has been said. It could show that the writer anticipates objections, and therefore attempts to limit the space for such objections.

Pronouncements were also made in the form of a rhetorical question. In this regard, the rhetorical question does not necessarily need an answer but somehow passes a point of view on to the addressee or the reader, as seen in example (36).

(36) How, then, can they influence any allocation within already impossibly overstretched, ludicrously inadequate university budgets? (M\&G)

The question simply states that those people should have not been involved in the first place as the resources are limited. Since Pronouncements leave a very limited space for an alternative view, the readers are assumed as aligned with the writers and those objecting to these "facts" will be increasing their interpersonal cost.

Resources of Proclaim: Concur were the second most frequently occurring options (25 percent). Within this sub-category, Lesotho Times employs most resources (47 percent) in this category, presupposing a shared knowledge between the paper and the readers, in particular the whole nation. Public Eye comes second with 36 percent and lastly, Mail and Guardian employs Proclaim: concur resources at the rate of 24 percent. However, Sunday Times does not employ Proclaim concur resources at all. It nonetheless, presupposes a shared knowledge among its readers by employing monoglossic utterances. According to Martin and White (2005: 107) monoglossic utterances may imply a shared knowledge as the writer assumes that the proposition being advanced will not be problematic or is not up for discussion.

This sub-category is divided into two groups: affirm and concede. In affirm, the speaker presents the current proposition as something that is given, as being in accord with what is generally known or expected. He presents himself as simply echoing or affirming the generally shared knowledge, as illustrated in examples (37) and (38).

(37) Such continuous operation, would of course, require more resources to ensure its effectiveness (PE).

(38) We all know how these deranged despots have been willing to murder their own people in a bid to instil the "fear of God" in their own subjects (ST). 
The use of of course in example (37) and we all know in example (38) highlights the dialogic nature of the editorials and reinforces a sense of shared goals and common interaction between the newspaper and readers. Hyland (2005: 184) believes that these resources seek to "position readers within apparently naturalised boundaries of disciplinary understandings". The writers rely on pre-agreed knowledge, and thereby reducing any processing difficulties or misunderstanding on the part of the readers as the readers' line of thinking is assumed to be in line with the writers' arguments.

With the combination of a declarative and a question, the dialogic space is contracted, as no one would want to put up an opposing view to a view supposedly held by everyone. In this case the reader is rhetorically aligned with the writer's views and potential alternatives are indirectly silenced, as seen in example (39).

(39) This would obviously include the sparing of government and the presidential blushes-what other motive can the government have? (M\&G)

Hyland (2005: 186) views these types of questions as strategies to invite and bring the readers into a space where they can be led into the writers' viewpoint. The writers manipulate the readers into accepting the writer's viewpoint or following a particular line of argument. Unlike the questions that seek to expand dialogic space in the sub-category of Entertain, these questions lead the reader to an obvious answer, the writer and the reader are presented as concurring.

In Concur: Concede, there is a combination of concession and countering expressions (Concede and Counter) whereby the writer shows a strong agreement with a proposition and then counters the same proposition as shown in examples (40) and (41).

(40) Many will welcome any plan that seems to demonstrate clear political will to unlog the sclerotic arteries of the economy. We certainly do - but there are big questions $(\mathrm{M} \& \mathrm{G})$.

(41) It is therefore clear that they certainly need better salaries. But the problem is that their employers have already said they cannot afford to pay M1 500 (LT).

In examples (40) and (41) both propositions are presented as valid but the second proposition that is preceded by the conjunction is presented as more valid. The use of these rhetorical pairs signals that the writer is negotiating with the reader. The writers first signal that they are in agreement with the addressee and immediately close down dialogic space to pass their own point of view that they consider to be more dominant than the conceded proposition. The use of these kinds of rhetorical pairs invokes both the presence of the writer and the reader or the addressee in the unfolding communicative event. 
The least employed sub-category was that of Endorse. In endorsements, the authorial voice aligns with prior speakers and "takes over the responsibility for the proposition or at least shares some responsibility for it with the cited source" (White 2005: 122). In this case the authorial voice is heavily involved in construing the proposition as incontestable because it is proven or shown.

In the Endorse sub-category, Mail and Guardian and Public Eye employ the resources in equal frequency (37.5 percent). For Mail and Guardian, the presence of endorsements can be attributed to the fact that the editorials in this paper usually refer to the information gathered during investigations of news stories. In this regard, the paper finds it appropriate to align with the attributed materials (and positioning the readers similarly) from these investigations as they are considered reliable. It is assumed that newspapers do not publish a story until all information is gathered and has been proven to be true. This can be seen in example (42) to (44).

(42) The extraordinarily blunt, but also careful, report eloquently demonstrates that many universities are forced into taking measures they know to be dreadful to their students $(\mathrm{M} \& \mathrm{G})$.

(43) It has been proven time and again that in many such strikes, only a small number of unruly individuals will be advocating mayhem for their own ulterior motives (PE).

(44) But the release and subsequent clash between the judges only serves to vividly illustrate what is wrong with our justice system in Lesotho (LT).

The use of pre- and post-modifiers in examples (42), (43) and (44) shows the writer as strongly aligned with the attributed material. The authorial voice indicates its endorsement of the current viewpoint. It further shows that it stands with the attributed source in advancing the current proposition.

\section{Conclusion}

The findings from the study show that editorial writers tend to limit dialogic space rather than opening it up. This is probably because the writers mostly pass their opinions to their readers and at the same time they position their readers as sharing the same opinion. The writers also want the readers to accept the position given by the editorial. The small difference in the use of contracting and expanding resources may imply that the editorial writers are trying to maintain a balance between their authorial persona and the readers (Thompson 2005: 312).

Lesotho Times has the highest frequency of Engagement resources. Its editorials seem to carry a more conversational tone, unlike other editorials. Lesotho Times editorials also used more person pronouns and directives than other editorials. 
Among all the four newspapers, Lesotho Times comes across as the paper that relies more on affective assessment of events than other newspapers do. The use of person pronouns and directives is far more pronounced than in other newspaper editorials. The tone of the paper is more conversational than in the other newspapers. This, in turn, resulted in the high number of Engagement resources used in the editorials

Sunday Times shows a low frequency in the use of the resources. This is probably because, in most editorials, the paper starts with a background section written in monogloss and starts an argument in the middle of the text or towards the end. The paper is also similar to Public Eye in that the editorials strive for a neutral comment and do not try hard to influence the readers or the addressee.

Public Eye and Sunday Times editorials employ more expanding resources than contracting resources. This may be because the editorials more or less follow an objective rather than a subjective tone (as the standard editorials do). The editorials employ a more informative structure than giving their own opinion. The papers rely on external sources as in a news story. In particular, person pronouns are less frequently used and in some editorials, they are not present at all. This is more typical of a news story than an editorial comment. It does not try hard to persuade the readers into reaching certain conclusions.

Although Lesotho Times and Public Eye, the Lesotho newspapers, differ in terms of the style that they use in the commentaries to get their message across, Sunday Times and Mail and Guardian use almost the same style. They use fewer pronouns and they strive to be objective in passing their comments.

\section{References}

Bakhtin, M., 1986. Speech Genres and Other Late Essays transl. V. W. Mcgee. Austin: University of Texas Press.

Halliday, M. A. K., 1994. Language as code and language as behaviour: a systemic functional interpretation of the nature and ontogenesis of dialogue. In R. P. Fawcett, M. A. K. Halliday, S. M. Lamb and A. Makkai, eds., The Semiotics of Culture and Language. London: Frances Printers.

Hyland, K., 2005. Stance and Engagement: a Model of Interaction in Academic. Discourse. Discourse Studies 7.2: 173-192.

Love, A., 2011. The language of newspaper editorials in Lesotho. In A. Love, M. Machobane, F. Moloi, T. Khati, B. Ekanjume and T. Qhala, eds., Language Contact, Identity and Socio-Economic Mobility pp. 406-417. Proceeding of $10^{\text {th }}$ LASU Conference 2009: National University of Lesotho.

Martin, J. R., 2000. Beyond Exchange: APPRAISAL systems in English. In S. Hunston and G. Thompson, eds., Evaluation in Text: Authorial Stance and the Construction of Discourse pp.142-175. Oxford: Oxford University Press 
Martin, J. R. and P. R. R. White, 2005. The Language of Evaluation: Appraisal in English. New York: Palgrave MacMillan.

Thompson, G., 2001. Interaction in academic writing: learning how to argue with the reader. Applied Linguistics 22.2: 58-78.

Thompson, P., 2005. Points of focus and position: intertextual reference in $\mathrm{PhD}$ theses. Journal of English for Academic Purposes 4.4: 307-323.

White, P. R. R., 2005. Beyond modality and hedging: a dialogic view of the language of intersubjective stance. Text 23.2: 259-284.

White, P. R. R., 2001. An introductory tour through Appraisal Theory. [http://www.grammatics.com/appraisal] Accessed 23/10/2011. 